Maria Filipowicz-Rudek (D) Universidad Jaguelónica, Cracovia

Centro de Estudos Galegos maria.filipowicz-rudek@uj.edu.pl

\title{
El difícil choque entre el Este y el Oeste en el nacer del nacionalismo gallego
}

Uno de los indudables privilegios y placeres del traductor o investigador de la literatura es ese trato con ella que tiende a poner de manifiesto los evidentes y explícitos contextos históricos, culturales, sociales y literarios. Más aún, solamente una lectura así de profunda permite hacer familiar el texto literario dentro del ámbito autóctono y propio, así como asegurar el sentimiento de validez de su existencia y de su influencia social, cada vez menos evidente en el mundo contemporáneo.

Una lectura así tiene también después de todo un valor subjetivo. A menudo se convierte para el investigador en un acicate para descubrir nuevos horizontes de conocimiento e islas ignotas de empatía cultural. La literatura de Galicia, en cuanto literatura minoritaria, tiene en este sentido todavía unos condicionamientos añadidos, resultantes de su "descontinuidade", de su condición agónica, que exige una incesante formulación de su "raison d'être", y también de la agobiante lucha con los complejos y con la "leyenda negra", lo cual en el discurso crítico más moderno, al parecer totalmente justo, es visto como el motor más potente de su dinamismo interno.

En este contexto no causa sorpresa la temática de Sete palabras, la penúltima novela, en parte autobiográfica, del ya eminente (ganador 
del Premio Nacional de Narrativa 2003) escritor gallego Suso de Toro, concentrada en torno a la búsqueda de la identidad de la propia familia y de sus raíces. El protagonista de la novela es un hombre maduro, un "alter ego" del escritor, quien durante la visita a su lugar natal y ante el rostro de su propio padre, que se está muriendo, ya sin vista ni memoria, comprende, no sin consternación, que ha vivido demasiado tiempo de su vida sin haberse interesado para nada por saber quién fue y de dónde procedía su abuelo, el padre de su padre, a quien le debe su apellido, y que la única fuente disponible de conocimiento sobre este tema está prácticamente a punto de extinguirse.

Como é que un pode medrar e chegar a pasar dos cincuenta anos, unha idade en que a xente morre, sen caer na conta de que non sabe quen é o seu avó? Vívese a vida en estado de ensoño, toda a vida é un feitizo. Un non pode verse a si mesmo desde fóra, desde lonxe, non hai maneira humana, e pasa a vida camiñando somnámbulo. É posibel que exista un anxo da garda, como se lles di aos nenos, ou un daimon ou cousa así que nos acompañe, pois vívese cego. É posíbel, si (Toro 2009: 18).

Así comienza el viaje del protagonista no solo en el tiempo, sino también en el espacio, ya que el deseo de recobrar la paz del alma lo lleva a una investigación genealógica, a la búsqueda de personas y documentos no solo en su país, pues en la segunda parte de la novela se dirige también a Cuba, adonde emigró sin retorno su abuelo, abandonando a la familia y a dos pequeños hijos, de los cuales uno, su propio padre, lleva dentro el trauma del abandono y la hostilidad, transmitidos inconscientemente a las siguientes generaciones. Este viaje obstinado y variopinto hacia las fuentes de la información, pero también hacia lo profundo de sí mismo, que se mueve en la frontera de la ficción y de la autobiografía, no ofrece, sin embargo, los resultados deseados, el pasado se cerró para siempre. Es como si las olas del Atlántico se hubieran tragado el cuerpo de su antepasado sin dejar noticias. El consuelo llega 
hacia el final con las siete palabras que dan pie al título, extraídas del recuerdo de una de sus interlocutoras: "e el que era tan boa persoa". Siete palabras que absuelven al progenitor desaparecido, quintándole el estigma de la traición y la mala voluntad, lo cual como resultado permite al protagonista enterrar a sus muertos en paz.

La novela está escrita con soltura y agilidad, aunque aparentemente no se libra de los tediosos detalles de las arduas investigaciones genealógicas del protagonista, y llega a veces a ese nivel de suspense que encontramos en la lectura de una novela policíaca. Tal vez esto sea debido a la narración en segunda persona (diádica), que, según varios expertos en narratología, es la más experimental de entre las posibles: por una parte, porque el término "tú" obliga al lector a una autorreferencia, aunque sea momentánea y pasajera, a una alusión a sí mismo, en otras palabras, a una superación de la frontera entre la ficción y la realidad; por otra parte, el desarrollo de la narración no deja lugar a dudas de que el destinatario es un protagonista más. La narración en segunda persona, como escribe Magdalena RembowskaPłuciennik, tiene diferentes funciones: puede implicar una identificación plena entre "yo" y "tú", donde el yo es el propio narrador y el tú es el lector; puede tener también un valor terapéutico y autocognitivo, pero también puede desenmascarar e intensificar conflictos internos (2017: 253-254). En la situación en que el narrador se dirige a sí mismo, y este es el caso concreto de Sete palabras de Suso de Toro, la narración diádica puede sugerir una falta de cohesión, una dispersión del yo.

Así pues, cercanía y distancia a la vez. Como acertadamente observa la anteriormente mencionada investigadora, "la narración en segunda persona introduce indispensablemente un elemento de coparticipación en acciones ajenas, causa un efecto de implicación emocional en la acción compartida, tanto mental (lo que le añade sus características de representación de la conciencia), como también física en la presentación espaciotemporal..." (Rembowska-Płuciennik 2017: 255). 
En el texto de Toro estamos ante un conflicto interno del protagonista-narrador, pero la ambivalencia de su relación mutua, por una parte, crea cercanía y, por la otra, genera una distancia. Desempeña esta una finalidad esencial: compromete con más intensidad al lector, entra en su privacidad, intensifica la identificación con el dilema-misión del protagonista, finalmente universaliza la problemática de la novela, pues si algo me ocurre a mí y a ti, también les puede ocurrir a muchos otros, y puede que también a cada uno de estos muchos.

Esta introducción, tal vez demasiado extensa, parece imprescindible para, así, partiendo de la novela del prosista gallego, mirar más de cerca, desde la perspectiva sugerida por la temática de este tomo, una construcción más amplia, a la cual, estoy convencida, en cierto modo, metafóricamente, puede aludir la novela de Suso de Toro, es decir, para mirar más de cerca la construcción de la identidad colectiva de Galicia, cuyos comienzos confluyen con el romántico despertar nacional de mediados del siglo XIX, y a la cual hace referencia el título de mi intervención.

Para desarrollar esta comparación, solo en apariencia atrevida, me inspiré en el fragmento de la novela de Suso de Toro en el que el autor al principio de sus búsquedas, al hacerse consciente de la falta de conocimiento de sus raíces familiares, intenta esbozar hipotéticamente la forma de este pasado, en el cual una de las pocas cosas ciertas es el hecho de que el abuelo se crió en un hospicio. Esta falsa pista, como pronto se muestra, sobre la construcción del apellido (Toro) le lleva a imaginarse por un momento que es judío:

Aí está, outra vez, a posibilidade dunha orixe xudía, atraeute sempre como unha explicación do teu mal, o teu estar a desgusto sempre. Unha sensación permanente de estar fóra de sitio, incómodo en todas partes. Incómodo contigo mesmo. Ese lugar común sobre algúns intelectuais xudeus de principios do século $\mathrm{XX}$, iso de que a súa condición era ser e mais non ser dun lugar, estar no ar, pairando, sen raíz verdadeira. Como a túa condición secreta de intruso, esa incerteza túa, esa dúbida en se es dalgún sitio de vez. Como se 
fosen pedir o pasaporte nalgún momento e fosen descubrir que é falso, que non es de alí. Como se foses un neno adoptado.

Esa explicación tan querida para o teu lado snob, vaia snobismo tan infundado. Que se as túas listas de intelectuais e artistas xudeus. É, sénteste xudeu, un xudeu de carallo, como se todos eses intelectuais e artistas formasen unha caste especial. Elitismo, verdaeiramente iso é o que che atrae, ese elitismo cultural. Mais non tes nada que ver con eles. Nin es xudeu, nin descendes de xudeus, agora xa o sabes, o teu apelido vén dun hospiciano así que vai deixando o conto de vez... (Toro 2009: 54-55)

Cito este amplio fragmento no sin razón. Este interesante y muy convincente intento de reconocer los procedimientos mentales por los que uno crea las representaciones de la propia identidad, que de un modo coherente une pasado con presente, el estado del alma con su origen, el carácter con el código genético, se puede interpretar no solo desde la perspectiva personal o autobiográfica, sino, ante todo, como un paralelo de la construcción de la conciencia comunitaria.

Suso de Toro es uno de los escritores e intelectuales que, eligiendo conscientemente el idioma en el que compone e inscribiéndose en el paradigma literario de una cultura menor, no evita en su creación la reflexión, a menudo incluso provocativa, sobre el tema del estatus y condición del tejido cultural, cuya pregunta fundamental es la pregunta sobre el sentido de la existencia y la perdurabilidad, la defensa de posturas dudosas dentro y fuera de España, la búsqueda de la identidad colectiva. Vale la pena recordar aquí una considerable colección de ensayos, cuyos propios títulos anuncian ya la obsesión del autor de $O$ país da brétema: Unha viaxe no tempo pola cultura celta (2000, El País-Aguilar), Nunca máis Galiza á intemperie (2002, Xerais), Españois todos: As cartas sobre a mesa (2004, Xerais), Ten que doer: literatura e identidade (2004, Xerais), Outra idea de España: Mar de fondo (2005, Xerais), Outra Galiza (2008, Xerais), Inmateriais (2013, Xerais). 
Esta conciencia comunitaria en cada sociedad sigue siendo un fenómeno dinámico, variable, que configura los fundamentos de las posteriores elecciones y tendencias políticas. Galicia, hoy una Región Autonómica de la monarquía de España, con un estatus constitucional de nacionalidade histórica, un término que suscita controversia en cuanto a su relación con el término nación, tiene una historia que abunda en acontecimientos esenciales para lo que llamamos hoy la península ibérica. Sin embargo, estos hechos, como comúnmente se considera, a consecuencia de la situación geopolítica de Galicia -de su anacrónico estatus como tierra del fin del mundo, finis terrae-, permanecieron siempre, per analogiam a dicho estatus, en la sombra de la historiografía central. Miguel Anxo Murado, intelectual y escritor gallego, en su ensayo antropológico y literario Otra idea de Galicia (2008), en ningún caso escrito a partir de posicionamientos nacionalistas, expresa este problema con bastante aspereza:

$¿$ Es que realmente Galicia no tiene historia? Galicia tiene una historia, evidentemente. No hay ninguna región del mundo que no la tenga. El problema es que la de Galicia no encaja fácilmente en la historia convencional de España. La historiografía nacionalista gallega lo considera una conspiración para suprimir su pasado; pero la realidad quizá sea más prosaica. Puede que sea sólo pereza. La historia de Galicia se compadece tan mal con la de España, la complica de tal manera, que los estudiosos del XIX y sus sucesores han optado por ignorarla en unos casos o retorcerla en otros... (Murado 2008: 50)

Puede ser precisamente por ello que la primera, y, como parece, la más importante construcción de la conciencia comunitaria de Galicia, nazca en el seno de la historiografía y al mismo tiempo del posicionamiento que en Europa se deriva precisamente del pensamiento nacional. Su autor es Manuel Murguía (1833-1923), historiador y escritor, iniciador y primer presidente de la Real Academia Galega, autor de muchos trabajos sobre la cultura, la sociedad y la historia de Galicia, 
marido de Rosalía de Castro, poetisa, madre de la renacida literatura gallega. Su aportación incuestionable al movimiento regionalista, en el cual creció, fue dar un paso radical en la dirección de la construcción histórico-teórica de Galicia como nación o nacionalidad, más aún, lo que entraña mayor importancia, en el enfoque que se diferencia y aparta de la idea centralista de España como un estado uninacional. En la obra editada en 1865 Historia de Galicia, escrita en español, por tanto no solo para los suyos, sino seguramente, sobre todo, para los de fuera, y considerada como crucial en el logro político-ideológico del pensamiento regionalista afirma con convicción:

La Península Ibérica no constituye una entidad nacional, y lo que es más grave, se advierte asimismo que se halla desde luego dividida en tres grandes porciones territoriales que informan respectivamente la sangre y la tradición... El fondo de la población, las costumbres propias a cada uno de dichos grupos, los pensamientos que abrigan, les dan fisonomía propia y condiciones de verdadera nacionalidad. Hasta tal punto y con tal fuerza, que cada una de las agrupaciones en que aparece entonces dividida la Península, da vida a una civilización y crea una lengua, signo el más característico y declarado de toda nacionalidad (Murguía apud Maíz 1984: 138).

Un rasgo importante en la concepción de Murguía, además de hacer hincapié en la validez del término nación para referirse a los habitantes de Galicia, es su fijación en el pensamiento nacional europeo, que de una forma original, como asegura Ramón Maíz (1984: 146-147), une elementos de la concepción liberal italiana de Pasquale Mancini, centrada en la "conciencia nacional" y el voluntarismo político (la cuestión del proyecto nacional), y en el enfoque organicista alemán (relacionado con ideas de Herder), que era entonces el más extendido en Europa, concentrado en los elementos naturalistas-históricos tales como la raza, la historia o el territorio.

Y aunque en la construcción nacional de Murguía desempeñan con operatividad una función clave los elementos naturalistas, sobre 
todo, como ya hemos dicho, la etnicidad, la historia y la lengua (alejados en su esencia de la concepción italiana), él tambien atribuye un significado nada marginal a la cuestión de la "conciencia nacional" o a su fijación liberal desde el punto de vista político (algo que no encontramos en las teorías alemanas). De forma lapidaria lo expresa el mismo Murguía en el texto publicado en Argentina sobre los desafíos del regionalismo gallego "Si somos hijos de nuestra región, lo somos también de nuestro tiempo" (Murguía apud Maíz 1984: 147).

Las teorías etnocéntricas surgidas en la segunda mitad del siglo XIX en el seno de la sociología (Arthur de Gobineau, Ludwik Gumplowicz, Houston Chamberlain) dividieron a la humanidad en grupos raciales y la jerarquizaron. En la cima de la pirámide de las civilizaciones se puso a la raza aria. Las nuevas teorías se convirtieron en caldo de cultivo no solo de una orientación etnocéntrica de la historiografía, sino también de la cultura, del arte y, como ya se sabe, en las primeras décadas del siguiente siglo, también de la política. El mito de la raza aria se desarrolló en Alemania como mito teutón; en Gran Bretaña, como mito anglosajón; y en Francia, como mito celta, construyendo las bases para las teorías nacionales en la Europa del siglo XIX.

Murguía es un lector atento a las interpretaciones de las nuevas teorías, como lo demuestra Ramón Maíz (1984: 154), sobre todo de las promovidas por los historiógrafos franceses e ingleses, quienes establecieron la clave étnica para la explicación de la historia del mundo y de la propia región. El mito fundacional central de la comunidad nacional - y para Murguía su pequeña (gran) patria de Galicia es una comunidad nacional - lo constituye el origen celta de sus habitantes.

El celtismo - escribe sobre ello desde la perspectiva de las más modernas afirmaciones de la historiografía el eminente historiador e intelectual gallego Ramón Villares en el ciclo de ensayos Identidade e afectos patrios (2017) - ya se encuentra antes, a partir de la segunda mitad del siglo XVIII tanto en el discurso español historiográfico 
como un poco más tarde en el gallego (José Verea y Aguillar). Sin embargo, Murguía, a partir del postulado etnocéntrico, crea el hecho no sólo histórico, sino, sobre todo, diferenciador y ennoblecedor. El puro celtismo ario de los gallegos en Murguía se opone a otras variantes de la raza no arias (anarianas), como la fenicia, la semita o la árabe, que desde la perspectiva histórica influyeron en la configuración de otras etnias, las etnias inferiores de España. El celtismo es comprendido por Murguía no solo como el único fermento de la totalidad histórica de la cultura material (arquitectura) y espiritual (costumbres, religión, mitología), sino como un componente físico de carácter antropológico: así lo llama y lo define como tipo étnico gallego: “... cabeza más redonda que oval, facciones redondeadas y mediana estatura, la nariz no viene recta desde la frente sino que la separa una depresión" (Murguía apud Maíz 1984: 159-160).

La polarizada construcción pronacional de Murguía establece una oposición de lo propio, positivo, racialmente puro, céltico, ario, occidentalocéntrico, frente a lo extraño, negativo, racialmente mezclado, semita (¿oriental?). Se trata no solo de una interpretación y glorificación de los hechos pasados, sino sobre todo de un proyecto para el futuro. Tiene que servir para salir de la inexistencia, para europeizar y modernizar Galicia social y materialmente, tiene que sancionar la tendencia separatista, también en el primitivo plan político: "Qué lazo de sangre, qué lazo histórico ha de unir naciones cuya cultura tiene tan distinto origen y fundamento?" (Murguía apud Maíz 1984: 170).

Sin embargo, para llegar a este plano era todavía demasiado pronto. La obra de Murguía con todo, como escribe Ramón Villares (2017: 168-176), tuvo su innegable aportación no solo en el despertar de los deseos nacionales, sino también en los orígenes de una cierta celtomanía, que se desarrolló a finales del siglo XIX y principios del XX no solo en el terreno de la historiografía, sino en muchas otras manifestaciones de la vida social, comenzando por la literatura, 
pasando por la etnografía y la historia del arte, y terminando en la cultura popular. Su ocaso fue lento y no llegó a consumarse. Hoy propiamente no se encuentra presente en el discurso nacional (su lugar lo ocuparon la lengua y la ideología de izquierdas, el partido nacional BNG promueve un nacionalismo radical marxista), si bien no deja de resultar bastante cercano a la mentalidad del pueblo:

Dunha celtomanía abusiva e case universal pasamos a unha sorte de celtismo débil, ben acorde coas tendencias predominantes da cultura desta fin de século. É probable que haxa en todo isto algo de comportamento pendular e que os vellos mitos non fosen despedidos oficialmente polos seus substitutos, aínda ignotos. A pesar destas viraxes, pódese dicir que o celtismo goza aínda de considerable enraizamento na mentalidade popular galega (a pesar de non contar con ningúna figura análoga á de Astérix para os galos), que segue de a servir de fonte de inspiración para obras literarias (Méndez Ferrín, Manuel María...), e que aínda está presente nos estereotipos con que os galegos son identificados pola mirada allea (Villares 2017: 176).

Estoy totalmente convencida de que es preciso reconocer este vector de influencia de la concepción nacional de Manuel Murguía como esencial, positivo y productivo para el proceso de consolidación de la comunidad gallega y de su identidad, como el motor de su promoción interna y externa. Sin embargo, la recepción del pensamiento polar de Manuel Murguía presentaba también partes más oscuras. A estas difíciles lecturas del maridaje entre raza y nación hay que añadir los trabajos profascistas y profundamente antisemitas de Vicente Risco (1884-1963), escritor, filósofo de la segunda fase del renacido movimiento nacional de Galicia en los años 20 y 30 (Murguía pertenece a la primera generación, conocida como Rexurdimento), escritos desde fuertes posicionamientos cristianos, también en el contexto del triunfo político del franquismo en España. Como ejemplo de ello, en su obra publicada en 1944 Historia de los judíos desde la destrucción del templo, divide la historia de la 
nación judía en dos etapas, antes y después de Cristo, para acusar al propio judaísmo (después de Cristo) de tener mala voluntad y de la perpetración de todo el mal que hay en el mundo, resultante del odio que ellos alimentan hacia los cristianos (Rodríguez González 1993: 179). La controvertida obra y pensamiento de Vicente Risco (escrita en un período de creación más tardío) exige seguramente una reflexión más profunda, pues en su interior es dispar, surgió en unas determinadas condiciones históricas, lo cual, por una parte. la justifica, pero, por otra parte, sin duda no.

A modo de conclusión, volvamos al citado fragmento de la prosa de Suso de Toro donde describe el esnobista deseo de tener unos progenitores judíos y así adherirse a la élite intelectual y artística del mundo. Este primer intento fracasado de querer construir la propia identidad ilustra perfectamente a mi parecer un mecanismo tanto psicológico como cultural. El elitista mito judío nace en la vida del escritor gallego como resultado de las imaginaciones, ambiciones, deseos ocultos, frente a su insuficiente conocimiento sobre sí mismo, sobre sus raíces, que son un misterio tentador, alimentado por la crisis a mitad de la vida. En unas circunstancias similares nace en Galicia el mito celta, un interesante fenómeno histórico que, como la lluvia característica de su clima, empapa su tejido cultural en el momento que empieza a formarse, adopta diferentes formas, se va apagando, pero permanece ininterrumpidamente desde hace más de ciento cincuenta años, definiendo su identidad por dentro y por fuera.

Tanto el judaísmo como el celtismo conviene incluirlos en Galicia entre las construcciones culturales históricas que en la actualidad se pueden palpar en los testimonios materiales dejados por estos grupos étnicos en su territorio. Los barrios judíos llamados xudarías en Ribadavia, Allariz o Ourense, los castros celtas dispersos por toda Galicia están presentes de forma cada vez más concreta en el discurso científico, pero junto a esto permanecen también en la imaginación 
popular, fomentada por la creación literaria. No cabe duda de que la imaginación literaria asegura que estos elementos estén vivos en la cultura. Acaso puede sorprendernos el hecho de que Benito Vicetto, contemporáneo del historiador y escritor gallego Manuel Murguía, autor de novelas históricas en el espíritu de Walter Scott, en los siete tomos publicados en 1873 de su obra Historia de Galicia (Vicetto 1873: 239) declare: "o principal para escribir a historia dun pobo non son os datos; o principal é a imaxinación", y de acuerdo con esta declaración convierte a los antepasados de los gallegos contemporáneos nada más y nada menos que en los descendientes del personaje bíblico Tubal, un nieto de Noé sobreviviente del diluvio.

\section{Résumé}

\section{La difficile confrontation Est-Ouest à la naissance du nationalisme galicien}

L'Espagne, du point de vue historique, reste sans aucun doute l'un des scènes clés de l'Europe médiévale où l'Est et l'Ouest se croisaient de manière féconde. L'importance du peuple juif dans ce processus a son rôle inévitable. Dans ce contexte, la composante antisémite de la construction du nationalisme galicien est intéressante, ce qui crée un mythe fondateur qui contraste l'Orient et l'Occident. À l'arrière-plan de cette grande création culturelle avec des conséquences évidentes, entrevoit l'histoire absente de la Galice, le petit pays situé à l'extrémité ouest de la Finisterrae romaine. Mots-clés : Suso de Toro, littérature, identité, nationalisme, Galice, Espagne 


\section{Abstract}

\section{The Difficult Clash Between East and West at the Birth of Galician Nationalism}

Spain from the historical point of view remains, without a doubt, one of the key sceneries in medieval Europe where the East and the West intersected in a fruitful way. The prominence of the Jewish people in this process played an unquestionable part in it. In this context the anti-Semitic component in the construction of Galician nationalism is interesting, while creating the founding myth contrasts the West and the East. In the background of this great cultural creation, full of consequences, we may glimpse the absent history of Galicia, the small demos of the western end of the Roman Finisterrae.

Keywords: Suso de Toro, literature, identity, nationalism, Galicia, Spain

\section{Referencias bibliográficas}

MAÍZ Ramón, 1984, Raza y mito céltico en los orígenes del nacionalismo gallego: Manuel M. Murguía, Revista Española de Investigaciones Sociológicas 25 : 137-180, https://doi.org/10.2307/40183058.

MURADO Miguel Anxo, 2008, Otra idea de Galicia, Barcelona: Debate. REMBOWSKA-PŁUCIENNIK Magdalena, 2017, O przechodzeniu na ty... Narracja diadyczna wśród literackich reprezentacji świadomości bohatera, (in:) (W) sieci modernizmu. Historia literatury - poetyka - krytyka. Prace ofiarowane Włodzimierzowi Boleckiemu, Agnieszka Kluba, Magdalena Rembowska-Płuciennik (red.), Warszawa: IBL PAN, 249-264.

RODRÍGUEZ GONZÁLEZ Olivia, 1993, La obra narrativa de Vicente Risco, Tesis de la Universidad Complutense de Madrid, (on-line) https://eprints.ucm.es/3328/1/T17993.pdf (1.05.2019). 
TORO Suso de, 2009, Sete palabras, Vigo: Xerais.

VICETTO Benito, 1873, Historia de Galicia VII, Ferrol: Nicasio Taxonera. VILLARES Ramón, 2017, Identidade e afectos patrios, Vigo: Galaxia. 